\title{
The vigorous search for internationalization
}

\author{
Maria Helena Palucci Marziale
}

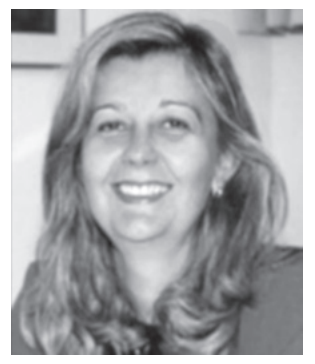

Nursing is an interdisciplinary, socio-humanistic and biologicist scientific knowledge field, also related to technology and innovation and relevant to society. Its scientific production is increasing in Brazil, both quantitatively and qualitatively, however, the dissemination of Brazilian authors' research in international journals in the area, with higher impact on the academic community, is still difficult. Brazilian researchers have intensified the search for more space in these journals and the periodicals edited in Brazil, with international circulation, have contributed to present the science produced in the country to the world.

Among the journals edited in Brazil that most contribute to disseminate the results of the scientific production of graduate programs and research groups, the Latin American Journal of Nursing - RLAE is highlighted for its broad circulation in the Brazilian territory and in countries in South, Central and North America, Europe, Africa and Asia.

As we reach the end of 2010 , this editorial presents the performance evaluation and the changes made in RLAE's editorial policy as to meet the new demands and expand, even more, its international visibility.

In 2010, RLAE's impact factor was published, for the first time, in the Journal of Citation Reports (JCR / ISI Thomson Scientific), which was $\mathbf{0 . 6 0 8}$, the highest impact obtained among nursing journals edited in Latin America. Concerning other scientific indicators in which RLAE was included, the $\mathrm{H}$ index $=9$ in SCImago Journal \& Country Rank (SCOPUS - Elsevir) and the fourth position in the Top Ten Ranking - SciELO Collection of access to journals are highlighted.

In Brazil, the graduate programs are evaluated by the Coordination for the Improvement of Higher Education Personnel (CAPES), related to the Ministry of Education. Among the evaluation criteria, the scientific production is an important indicator. CAPES ranks the journals in which students and professors of graduate programs have published their researches. The 'QUALIS ranking of scientific journals' is established based on scientific indicators from the main Brazilian and international databases. RLAE was classified in the A2 level in this ranking, that is, he second highest level of the classification, which is the highest level reached by a nursing journal edited in Brazil.

Of the 427 articles submitted for evaluation this year, $38 \%$ were published, $12 \%$ are in the process of publication and $50 \%$ were rejected. The articles were evaluated by reviewers of different nursing specialties and related areas. The 160 articles published this year were related to topics included in the main Brazilian and international agenda of health research priorities, such as: Health and Nursing Care, Mental Health, Women's Health, Child and Adolescent Health, Health of the Elderly, Public Health, Work Management, Health Education, Bioethics and Research Ethics.

Despite the excellent performance achieved by RLAE, planning new actions is necessary to achieve the goal of increasing its international visibility, thus, adjustments were made in the editorial policy. The bylaws were modified and, among the adjustments made, the composition of the Editorial Board is highlighted. As from January 2011, it will be composed of a Chief Scientific Editor, a Scientific Editor, four Associate Editors from the University of Sao Paulo 
at Ribeirão Preto College of Nursing and an Associate Editor external to the College. One of the responsibilities of the board is to carry out the pre-analysis of the articles. The inclusion of this new phase in the evaluation process of the articles will contribute to reduce the processing time between submission and publication, also reducing reviewers' workload. In addition, for next year, the online article submission system is planned to be available also in English and Spanish.

We thank authors and readers for choosing RLAE as their vehicle for scientific dissemination and reviewers and collaborators for the dedicated work and important contributions.

Maria Helena Palucci Marziale is the editor of the Latin American Journal of Nursing, and Full Professor of the University of São Paulo at Ribeirão Preto College of Nursing, WHO Collaborating Centre for Nursing Research Development, Brazil, e-mail: marziale@eerp.usp.br. 